\title{
Intimate Partner Violence and Traumatic Brain Injury: A Public Health Issue
}

Kathleen Monahan

School of Social Welfare, Stony Brook University, 10 Bobilin Lane, Rocky Point, NY 11778, USA

\section{Article Info}

\section{Article Notes}

Received: April 20, 2018

Accepted: June 25, 2018

\section{${ }^{*}$ Correspondence:}

Dr. Kathleen Monahan, D.S.W., L.C.S.W., L.M.F.T

Director of the Family Violence Education and Research Center

School of Social Welfare, Stony Brook University, 10 Bobilin

Lane, Rocky Point, NY 11778, USA

Telephone: (631) 444-3152

Email: kathleen.monahan@stonybrook.edu

(c) 2018 Monahan K. This article is distributed under the terms of the Creative Commons Attribution 4.0 International License

\begin{abstract}
Intimate Partner Violence (IPV) remains at epidemic proportions in the United States. Traumatic Brain Injury (TBI) as an outcome of IPV is now being investigated by researchers, particularly long-term sequelae. This review addresses underreporting and lack of treatment, and the physical and psychological impact for victims of IPV who have received a TBI. Recent research has begun to investigate professional sports players who experience repeated concussions and their at-risk status for Chronic Traumatic Encephalopathy (CTE). Women who are in abusive relationships for long periods of time may also incur repeated blows to the head. Researching the at-risk status for CTE is a much needed line of inquiry for this underserved population.
\end{abstract}

Intimate Partner Violence (IPV) remains at epidemic proportion in the United States with over 1 in 3 women experiencing, "...sexual violence, physical violence, and/or stalking victimization by an intimate partner during her lifetime"1. The National Intimate Partner and Sexual Violence Survey (NISVS) as well as other research indicates that one in four women in the United States experienced severe violence during her lifetime ${ }^{1-4}$. Significant interest in the occurrence of Traumatic Brain Injury (TBI) among women who have experienced IPV has emerged during the past decade. TBI research, particularly, Chronic Traumatic Encephalopathy (CTE), has been studied in male, professional sports players but has been largely overlooked in the female population. Considering the prevalence of IPV as a public health issue, coupled with the long-term negative sequelae of TBI, further investigation is warranted. Women may spend decades in an abusive relationship where head injury frequently occurs but is not typically diagnosed or treated. This review identifies gaps in identification and underreporting of TBI when IPV occurs. Short and long-term sequelae post-TBI, CTE, and future research regarding victims of IPV and subsequent TBI are also presented.

IPV is defined as "...consistent and coercive verbal, emotional, and physical violence directed toward a current or former intimate partner." ${ }^{\prime 1}$ NISVS defines physical violence as kicking, choking, stabbing, being burned, or being shot ${ }^{1}$. IPV creates long-term health and disability issues for its victims ${ }^{1-4}$. The financial burden of IPV to society is staggering with health care costs, particularly for the first twelve months after the assault, ranging between 2.3 billion and 7.0 billion dollars ${ }^{1,5}$. Workplace productivity and absenteeism may also be affected by current and/or past IPV ${ }^{6}$.

TBI is defined as "a bump, blow, or jolt to the head that disrupts the normal function of the brain" as a result from an external force to the head ${ }^{7}$. Each year, the CDC uses population-based data that includes 
deaths and health-care visits to assess the rate of TBI in the United States $^{7}$. TBI impacts 3-4 million people per year; ${ }^{7-8}$ and when factoring in the lack of reporting and/or lack of treatment, the incidence may be substantially higher ${ }^{7-8}$.

Several issues, such as defining the types of head injury and screening can contribute to the complexity of TBI as a result of IPV. Definitions and symptom criteria may differ across disciplines as well as individual providers, making diagnosis and treatment difficult, at best. For instance, the term concussion, mild TBI (mTBI) and TBI are often used interchangeably ${ }^{9}$. Practitioners may also look at symptom clusters such as loss of consciousness (LOC), posttraumatic amnesia (PTA), and scores on the Glascow Coma Scale (GCS) to guide diagnosis ${ }^{10}$. Thorough screening for TBI does not occur in all healthcare settings and therefore identification, assessment and referral for treatment may not occur. Failure to identify TBI may result in poor symptom management and identification of accommodation needs.

Compelling data indicates that IPV assaults are usually directed at the woman's face or head creating medical and neurological difficulties ${ }^{11-17}$. Mechanic, et al. ${ }^{18}$, examined moderate-to-severe injuries among helpseeking women who experienced IPV and nearly half reported repeated blows to the head. While women may seek medical intervention for their injuries and may go on to leave the abusive relationship, others may not, exposing them to repeated risk of TBI throughout the duration of the relationship ${ }^{18}$. Unidentified, untreated and unaccommodated TBI as a result of IPV victimization will affect psychological and physical outcome as well as social and familial adjustment.

\section{Identification and Underreporting}

Universal Screening of IPV which includes attention to head injury should occur in all health-care settings ${ }^{3,16}$. Additionally, standardized guidelines to identify IPV and TBI would assist in identification, assessment, and referral. However, this lack of uniformity across the variety of healthcare systems makes identification and intervention difficult, at best, and precludes consistent, reliable data collection.

IPV victims who have experienced TBI but do not seek immediate medical assistance present complex issues for the practitioner. Appearing in the medical practitioner's office some time after IPV with myriad neurological difficulties, the patient's case may be difficult to treat. $84 \%$ of one sample experienced severe injuries, yet only $21 \%$ sought medical attention immediately following the assault despite clinical symptoms ${ }^{15}$. The patient may not associate current neurological symptoms with previous TBIs and symptoms may have gone untreated impacting current treatment.
Medical attention is not sought for a variety of reasons: the batterer may prevent medical intervention, financial costs, lack of insurance, transportation issues, and shame, resulting in under-reporting and lack of treatment ${ }^{19}$. When women do seek treatment, they often attribute the assault as "a fall down the stairs" thus intervention and safety issues are not addressed, nor is the injury recorded as an assault, particularly IPV ${ }^{20,21}$.

An exploratory study conducted in 1999 of domestic violence shelter residents ${ }^{14}$ assessed the incidence of head injury and traumatic brain injury (TBI), yet little has been done to further this research until recently. Many domestic violence shelters are only beginning to include questions regarding TBI on their intake forms and/or to conduct assessments for referral to a neurologist. For instance, the Iowa Coalition Against Domestic Violence and the Brain Injury Alliance of Iowa developed a project, along with 10 domestic violence shelters to screen clients for TBI and provide them with resources. Of the 148 female individuals who were screened in 2012,88 or $60 \%$ positively endorsed a $\mathrm{TBI}^{22}$. Studies have detailed the issue of TBI among a variety of IPV populations, ${ }^{3,12,14,23}$ yet this information has not been widely disseminated or incorporated into DV shelter intervention policy ${ }^{14-16}$. Anecdotal accounts from shelter residents describe IPV assaults in which their head was smashed into the dashboard of the car, hit with a closed fist, a baseball bat, an iron frying pan, etc ${ }^{14,16}$.

\section{Short and long-term sequelae}

Psychological sequelae from IPV and TBI range from anxiety to constant fear, hypervigilance, confusion, disorientation, memory loss, flat affect and depression. Posttraumatic Stress Disorder (PTSD) may or may not be present, yet practitioners often confuse the overlapping symptomatology of TBI and PTSD ${ }^{24-25}$. While comorbidity of these diagnoses may be present, attention to TBI symptomatology may be overlooked or underestimated. Additionally, neuropsychiatric symptoms may be attributed by the healthcare provider and the patient as, "sequelae of the traumatic experience of IPV, menopause or aging and do not suspect a connection to head trauma/s sustained in the past"20.

Long-term outcomes for this population may result in debilitating impairments. Goldin states, "The most common difficulties associated with TBI include persistent cognitive, behavioral, and emotional challenges; disease morbidity; and social difficulties, all of which have been reported by women survivors of IPV"16. Considering the emotional, physical, and long-term neurological difficulties emanating from IPV and TBI, occupational and independent living may be significant factors ${ }^{26-27}$. There may also be sexrelated differences for individuals with TBI, particularly premenopausal women ${ }^{28}$. 


\section{Chronic Traumatic Encephalopathy (CTE)}

Community dwelling women who remain in longterm, abusive relationships may be at risk for significant neurological difficulties as a result of repeated TBI, particularly as they age. However, little is known regarding older adult females and IPV and TBI. During the past decade, significant interest regarding professional sports players with repeated TBIs and post-concussion syndrome has resulted in research on Chronic Traumatic Encephalopathy (CTE) ${ }^{29-30}$. Individuals in this cohort have been diagnosed with CTE, post-mortem.

Roberts, et al., described an elderly woman admitted to the hospital with multiple injuries. ${ }^{31}$ She suffered years of physical abuse by her husband and exhibited physical trauma, significant memory loss, and mental confusion. Post-mortem evaluation revealed brain pathology that, "have only been reported in dementia pugilistica, suggesting that trauma was a significant contributory factor in this case"31. A significant area of future research investigation is whether women who are in long-term, abusive relationships where chronic TBI has occurred are at-risk for significant neurological outcomes such as dementia, Parkinson's disease, or CTE. An emerging dialogue regarding brain donation from women who have experienced IPV and TBI between researchers, domestic violence shelter staff and victims highlights this issue.

\section{Discussion}

Currently, universal guidelines for screening of IPV and TBI across health care settings does not exist ${ }^{3,16}$. It is reasonable to assume that neurologists are treating IPV victims without direct knowledge of their trauma history and therefore not associating symptoms with chronic TBI. As noted, many of these women may not have sought treatment for head injuries, nor associated their symptoms with past TBI. With reports of cognitive decline, confusion, and memory loss, by a patient or a family member, a thorough history of head injuries that include IPV victimization, should be conducted. It is imperative that information regarding IPV be gathered without the batterer present or with a trusted family member. Asking for this information in front of the batterer will not only provide false information (the victim will, in all likelihood - not answer truthfully) but will put the patient at further risk for violence. It is also important to note that IPV does not decline with age, so assuming that an older adult's abuse is in the past would be erroneous ${ }^{32}$.

Intake forms that query for IPV as well as previous head injury create the atmosphere that the healthcare provider is open to dialogue. Office staff should be familiar with dealing with IPV victims in the office and a referral list of local resources should be posted in the examination and waiting rooms (e.g., the local victim's services office, the county domestic violence shelter, how to contact a Rehabilitation Specialist). While practitioners may find asking this information difficult, it provides for best practices and safety for the IPV population.

Attention to the short and long-term issues of postIPV and TBI require different interventions. Initially, safety issues are the primary concern along with the cessation of IPV. Long-term issues may include attention to physical difficulties; psychological issues including PTSD and depression; and, difficulty with Executive Function, specifically decision making, abstract reasoning, and carryover from situation to situation. These issues may best be treated by an interprofessional health care team that can address neurological, physical, and mental health issues as well as rehabilitation needs.

Research needs to address the scope of IPV and TBI nationwide and the impact of chronic TBIs on this population to address disability needs. Additionally, sex and gender equity in research is often overlooked in research design, implementation, and scientific reporting and the primary rationale for the development of the SAGER guidelines ${ }^{33}$. Farin, et al., state, "...the recognition of various risk factors and the treatment guidelines for severe head injury are heavily influenced by findings in male patients" ${ }^{28}$.Sex differences with TBI outcomes is a significant line of research inquiry and will assist patients in the process of recovery, adjustment and well-being. The long-term negative sequelae of IPV and TBI on older adult females, particularly the existence of CTE in this population, also needs extensive inquiry.

\section{Conclusion}

Purposeful injury to the brain deprives a victim of individuality and the right to live an independent and autonomous life. IPV is considered a public health issue yet it continues to remain at epidemic proportions. Universal screening of IPV and TBI in all healthcare settings would serve to identify this public health issue and provide much-needed secondary prevention. Professional schools dealing with the health of the public should highlight the magnitude of health issues and financial burden regarding IPV and post-IPV neurological issues. Research should also focus on the different outcomes of TBI for men and women.

We now understand how physical and psychological traumas, including neglect, affect psychosocial adjustment and, most importantly, the architecture of the brain. However, the issues of brain health, brain diseases and disability emanating from IPV have not been included in course work in most healthcare disciplines. Finally, brain donation by women who have suffered IPV and TBI will further research and assist health-care professions to understand the long-term neurological consequences of violence toward women in the United States. 


\section{Acknowledgment}

The author wishes to thank Kimberly F. Leake, L.M.S.W., for her thoughtful review of this manuscript

\section{References}

1. Smith SG, Chen J, Basile KC, et al. The National Intimate Partner and Sexual Violence Survey (NISVS): 2010-2012 State Report. Atlanta, GA: National Center for Injury Prevention and Control, Centers for Disease Control and Prevention. 2017.

2. Brieding $\mathrm{MJ}$, Basile $\mathrm{KC}$, Smith SG, et al. Intimate partner violence surveillance: Uniform definitions and recommended data elements. Retrieved from. 2015. https://www.cdc.gov/violenceprevention/ pdf/intimatepartnerviolence.pdf

3. Campbell J, Anderson J, McFadigion A, et al. The Effects of Intimate Partner Violence and Probable Traumatic Brain Injury on Central Nervous System Symptoms. J of Women's Health. 1-7.

4. Black MC, Basile KC, Brieding, MJ, et al, The National Intimate Partner and Sexual Violence Survey (NISVS): 2010 Summary Report. National Center for Injury Prevention and Control, Centers for Disease Control and Prevention. Atlanta GA. 2011. www.cdc.gov/ViolencePrevention/ pdf/NISVSExecutiveSummary-a.pdf

5. Brown D, Finkelstein E, Mercy J. Methods for estimating medical expenditures attributable to intimate partner violence. J Inter Vio. 2008; 23: 1747-1766.

6. Reeves C, O'Leary-Kelly AM. The effects and costs of Intimate Partner Violence for work organizations. J of Inter Vio. 2007; 23: 327-344.

7. Dams-O'Connor K, Cantor JB, Brown M, et al. Screening for Traumatic Brain Injury: Findings and Public Health Implications. J Head Trauma Rehabil. 2014; 29(6): 479-489.

8. Faul $\mathrm{M}, \mathrm{Xu} \mathrm{L}$, Wald $\mathrm{MW}$, et al. Traumatic Brain Injuryin the United States: Emergency DepartmentVisits, Hospitalizations, and Deaths 2002-2006. Atlanta, GA: Centers for Disease Control and Prevention, National Center for Injury Prevention and Control. 2010.

9. Menon D, Schwab K, Wright D, et al. Position Statement: Definition of Traumatic Brain Injury. Arch Phys Med Rehabil. 2010; 91.

10. Kristman V, Godbolt A, Salmi, L, et al. Methodological issues and research recommendations for mild traumatic brain ijury: the WHO Collaborating Cente Task Force on Mild Traumatic Brain Injury. J Rehabil Med. 43: 113-125.

11. Davis A. Violence related mild traumatic brain injury in women: Identifying a triad of post-injury disorders. J. Trauma Nurs. 2014; 21(6): 300-308.

12. Bhole S, Bhole A, Harmath C. The black and white truth about domestic violence. Emerg Radiol. 2014; 21: 407-412.

13. Matteoli M, Piacentino D, Kotzalidis G, et al The clinical and radiological examination of acute intimate partner violence injuries: A retrospective analysis of an Italian cohort of women. Violence Vict. 2016; 31(1): 85-102.

14. Monahan K, O'Leary KD. Head injury and battered women: An initial inquiry. Health \& Soc Wk. 1999; 24: 269-278.

15. Ivany A, Schminkey D. Intimate Partner violence and traumatic brain injury. Fam Community Health. 2016; 39(2): 129-137.

16. Goldin Y, Hag H, Trott C. Screening for history of Traumatic Brain
Injury among women exposed to Intimate Partner Violence. Physical Med \& Rehabil. 2016. http://dx.doi.org/10.1016/j.pmrj.2016.05.006

17. Iversen K, Pogoda T. Traumatic Brain Injury among Women Veterans, An Invisible wound of Intimate Partner Violence. Medical Care. April 2015; 53(4): Suppl 1

18. Mechanic MB, Weaver TL, Resick PA. Risk factors for physical injury among help-seeking battered women: An exploration of multiple abuse dimensions. Violence Against Women. 2008; 12: 1148-1165.

19. Mathias AK, Bedone A, Osis MJ, et al. Perception of intimate partner violence among women seeking care in the primary healthcare network in Sao Paulo state, Brazil. International J of Gynaecology and Obstetrics.2013; 121: 214-217.

20. Monahan K, Goldfine A, Biegon A. Traumatic brain injuries in victims of intimate partner violence: An underappreciated source of neurological morbidity. Future Neurol. 2017; 12(4), 189-191.

21. Monahan K. Intimate Partner Violence, Traumatic Brain Injury, and Social Work: Moving Forward. Soc Wk. 2018; 63(2): 179-181.

22. Traumatic brain injury in domestic violence programs in Iowa: Screening pilot. (2013). Downloaded 4/12/18

23. Kwako LE, Glass N, Campbell Melvin KC, et al. Traumatic brain injury in intimate partner violence: A critical review of outcomes and mechanisms. Trauma, Violence \& Abuse. 2011; 12: 115-126.

24. Wong J, Fong D, Lai V, et al. Bridging intimate partner violence and the human brain: A literature review. Trauma Violence \& Abuse. 2014; 15(1): 22-33.

25. Wong J, Mellor D. Intimate partner violence and women's health and wellbeing: Impacts, risk factors and responses. Contemp Nurse. 46(2): 170-182.

26. Helfrich C, Rivera Y. Employment skills and domestic violence survivors: A shelter-based intervention. Occupa Therapy in Mental Health. 2006; 22(1): 33-48.

27. Gutman S, Diamond H, Holness-Parchment S, et al. Enhancing independence in women experiencing domestic violence and possible brain injury: An assessment of an occupational intervention. Occupa Therapy in Mental Health. 2004; 20(1): 49-79.

28. Farin A, Deutsch R, Biegon A, et al. Sex-related differences in patients with severe head injury: Greater susceptibility to brain swelling in female patients 50 years of age and younger. J Neurosurgery. 2003; 98: 32-36,

29. Montenigro PH, Alosco MI, Martin BM, et al. Cumulative head impact exposure predicts later-life depression, apathy, executive dysfunction, and cognitive impairment in former high school and college football players. J Neurotrauma. 2017; 34(2): 328-340.

30. Mez J, Daneshvar DH, Kiernan PT et al., Clinicopathological evaluation of chronic traumatic encephalopathy in players of American football. JAMA. 2017; 318(\$): 360-370.

31. Roberts GW, Whitwell HL, Acland PR, et al. Dementia in a punchdrunk wife. Lancet. 1990; 14(335): 918-919.

32. Poliscastro C, Finn MA. Coercive control and physical violence in older adults: Analysis using data from the National Elder Mistreatment Study. J. of Interpersonal Vio. 2017; 32(3): 311-330.

33. Heidari S, Babor T, De Castro P, et al. Sex and Gender Equity in Research: Rationale for the SAGER guidelines and recommended use. Research Integrity and Peer Review. 2016; 1-9. 